\title{
Moisture as assessment criterion for coal rank and coal layers hazardous characteristics manifestation
}

\author{
Vadym Tarasov ${ }^{1, *}$, Mykola Antoshchenko ${ }^{1}$, Olha Zakharova $^{2}$, Anastasiia Zakharova $^{3}$, and Oleg Levadnyi ${ }^{4}$ \\ ${ }^{1}$ Volodymyr Dahl East Ukrainian National University, Department of Mining, 93400 Severodonetsk, Ukraine \\ ${ }^{2}$ Volodymyr Dahl East Ukrainian National University, Department of Chemistry and Industrial Safety Measures, 93400 Severodonetsk, \\ Ukraine \\ ${ }^{3}$ Tomas Bata University in Zlin, 76001 Zlín, Czech Republic \\ ${ }^{4}$ Kazakhstan, Production Field Tengiz, Ariadna LLP
}

\begin{abstract}
For the time being, moisture effect to the useful quality of coals has been researched comprehensively in detail. Herewith, there are a lot of unsolved problems related to the safety working out of coal layers. Presence of different forms of moisture in fossil coals essentially influences the coal layers hazardous characteristics manifestation during the mining activities. The Article deals with the results of analyses of more than thousand samples of the Donets Basin coals from different deposits, to research the relationship of total moisture and organic matter components in the coal carbonizations during the metamorphic processes. The researches have allowed separation of 3 stages for the fossil coal conversions. It is noted that at the initial stage, the carbon content is about $80 \%$, moisture proportion in carbonization is rather high - 0.36 ; but it decreases abruptly down to 0.12 , in case of the carbon content increasing up to $86.5 \%$. And the proportion of components (hydrogen, oxygen, nitrogen, and sulphur) total increases essentially up to 0.88 . At the next stage, at $86.5 \div 91.5 \%$, the components proportion in carbonization changes insignificantly. At the final stage of coal metamorphic conversions, 4-time growth of moisture proportion takes place in carbonization. It is found that moisture proportion in any form to be found in the coals shall be considered as a rank index, which is necessary to determine the coal layers hazardous characteristics.
\end{abstract}

\section{Introduction}

Moisture is one of the most important quality indicators of coals. The significant content of moisture has an adverse effect to heating-performance and processing characteristics of coal; it reduces its calorific value and thermal resistance; its grinding, screening, and dressing becomes more difficult; it increases its carbonizing time and other coal processes, and makes its transportation (as ballast) more expensive [1].

To determine the above properties, the total coal moisture content $(W)$ dried out to the constant weight at $105 \div 110^{\circ} \mathrm{C}$ shall be found. At the above temperatures, no pyrogenetic and hydrate moisture is removed and takes part in the total moisture content.

For the time being, the moisture influence to the coal useful properties has been researched comprehensively in detail. Herewith, there are a lot of unsolved problems related to the safety working out of coal layers.

Presence of different forms of moisture in fossil coals essentially influences the coal layers hazardous characteristics manifestation during the mining activities.

The significant role of moisture has been found in the gasdynamic events [2] and endogenous fires [3] occurrence, presence of dust-forming capability [4] and explosive properties of the coal dust [5]. These and several other negative manifestations of the coal layers hazardous characteristics are connected with changing the composition and properties of coals during their metamorphic conversions.

Generically, the metamorphism implies the various geological processes, which influence changes in the structure, mineral and chemical composition of coals [1]. Different forms of moisture content in the coals are connected with their metamorphic conversions as well. Determination of moisture content of each form and assessment of their influence to the coal layers tendency to manifest their hazardous properties is related to the mining problems, which are not solved yet [3]. Decreasing of accident risk and rate of injuries in the coal mines strongly depends on their solving and regulatory environment improvement. At its core, the moisture content relates to the metamorphic coal conversion indicators. Its content and forms of presence largely determine the elemental composition of coals and their properties [2-5]

The role of moisture in changing the composition and properties of coals during their metamorphic conversions has no proper reflection in the current Ukrainian regulations [6-9].

It's known that bed moisture in coals decreases as far as the metamorphism intensity increases; however, in

\footnotetext{
$\bar{*}$ Corresponding author: tarasov@snu.edu.ua
} 
passing to the anthracites, it increases again $[4,10]$. These works used different interpretation of the coal rank definition. In the work [10], one of the main definitions of metamorphism has been kept: increasing the carbon content in the organic matter almost up to $100 \%$, and reducing the total content of other main components down to zero. Keeping these provisions, 10 stages of metamorphism has been established based on the coke yield dry mineral matter free. Based on the analysis of multiple samples, average composition of the Donets Basin coals has been determined in the different coal ranks. The following has been taken under consideration: the content variation of carbon $\left(\mathrm{C}_{0}\right)$, hydrogen $\left(\mathrm{H}_{0}\right)$, nitrogen $\left(\mathrm{N}_{0}\right)$, sulphur $\left(\mathrm{S}_{0}\right)$, and oxygen $\left(\mathrm{O}_{0}\right)$.

In the work [4], the metamorphism intensity has been assessed by the coal ranks. The ranks as per industrial classifications define their useful quality, and do not reflect any alterations in the coal compositions and properties immediately. The useful quality of coals shall be established per totality of several classification indicators: the content of volatile agents $\left(V^{\text {daf }}\right)$, coal plastometric index $(y)$, semi coking resin yield $\left(T_{S K}^{\text {daf }}\right)$, and free upheaving indicator $(S I)$ [11]. Finally, they indirectly define the coke capacity that is one of the main tasks of industrial classifications. Coal humidity $(W)$ has been considered as an additional criterion of the dustforming capability [4], which has no direct relation to the metamorphic conversions. The content of volatile agents and coal rank are only indirect characteristics for variation of coal compositions and properties. In the case under consideration, they are assumed to be the key indicators of metamorphism intensity. By nature, $V^{\text {daf }}$ and coal ranks are derivatives of component compositions of the initial substance organic and mineral parts during the geological processes. The moisture is an integral component of the fossil coals; its content suffers significant variations in parallel with the other constituents $[10,12]$. For this reason, the moisture content in any form may serve as a criterion for the real hazard of coal layers during mining activities. This circumstance has been fully ignored in the regulations [6-9], when estimating the coal ranks.

In all the cases, the bed moisture $(W)$ is considered as an independent indicator, which is not included in the organic matter composition, and independent of the other components content [1, 10, 13, 14]. The yield of pyrogenetic and hydrate moisture shall be included in the composition of volatile substances [10]. These forms of moisture content are not considered in the volatile substances yield, when determining $V^{\text {daf }}$ indicator [1, 5, 13-15]. In both cases, the different forms of moisture content have immediate relation to the coal metamorphic conversions; and their indicators may determine the coal layers hazardous characteristics by many aspects.

One of causes of the normative documentation defects in a part of ensuring the safety conditions for mining operations is the proven insufficient previous study of the fossil coal moisture influencing their metamorphic conversion intensity.

Due to this, researches connected with the moisture study as an indicator of the coal metamorphic conversions are important today. The regulatory environment improvement largely depends on their results; it will help to reduce accident risks and rate of injuries in the coal mines.

\section{Research procedure}

Carbonization is one of the component parts of fossil coal metamorphic conversion processes. By definition [16, 17], it consists in the carbon $\left(\mathrm{C}_{0}\right)$ content increasing and hydrogen $\left(\mathrm{H}_{0}\right)$ and oxygen $\left(\mathrm{O}_{0}\right)$ reducing in the organic matter. In addition to $\mathrm{C}_{0}, \mathrm{H}_{0}$, and $\mathrm{O}_{0}$, variation of the nitrogen $\left(\mathrm{N}_{0}\right)$ and sulphur $\left(\mathrm{S}_{0}\right)[10]$ content takes place in the organic matter during the metamorphic processes.

As rule, the total content of $\mathrm{C}_{0}, \mathrm{H}_{0}, \mathrm{O}_{0}, \mathrm{~N}_{0}$, and $\mathrm{S}_{0}$ is at least $99 \%$ of the whole organic matter. For this reason, the carbonization indicator values $\left(C_{n}^{\Sigma}\right)$ in all the coal ranks shall be determined by the ratio:

$$
C_{n}^{\Sigma}=\frac{C_{0}}{H_{0}+O_{0}+N_{0}+S_{0}}
$$

Consideration of such an aggregate of components helps to determine $C_{n}^{\Sigma}$ more correctly.

The work procedure is actually based on the functional dependence of the totality of considered organic matter components on the carbon content $[18,19]$. This provision is confirmed by the experimental data concerning variation of the components $\left(\mathrm{H}_{0}, \mathrm{O}_{0}, \mathrm{~N}_{0}, \mathrm{~S}_{0}\right)$ totality depending on the carbon content in organic matter (Fig. 1, Curve 2). The information concerning variation of the components $\mathrm{H}_{0}, \mathrm{O}_{0}, \mathrm{~N}_{0}$, and $\mathrm{S}_{0}$ totality depending on $\mathrm{C}_{0}$ content as per [10] is shown in Table 1.

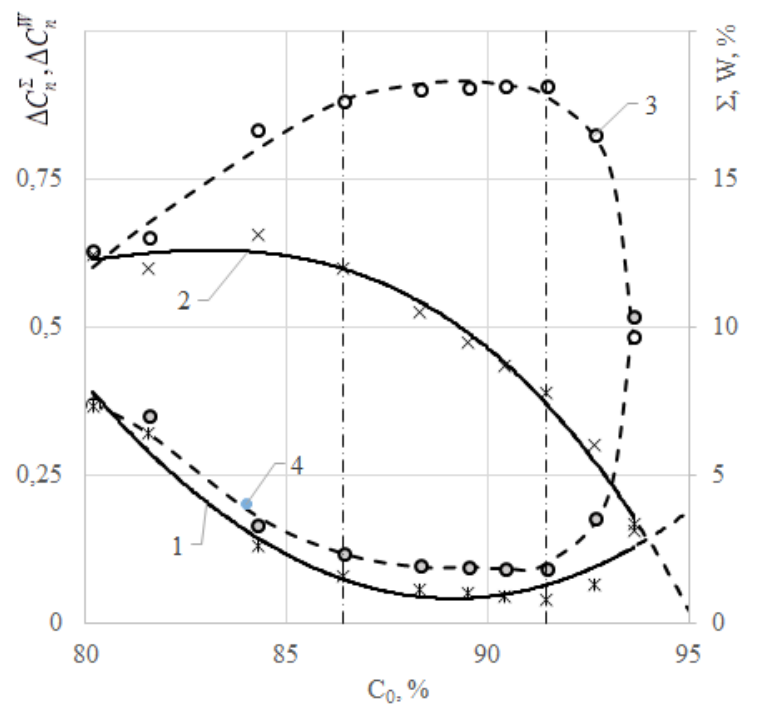

Fig. 1. Dependence of moisture variation $(W)$ and total $(\Sigma)$ of other components in the coal organic matter as per [10] and determination results of their part in coal carbonization $\Sigma\left(\mathrm{H}_{0}, \mathrm{O}_{0}\right.$, $\left.\mathrm{N}_{0}, \mathrm{~S}_{0}\right)$ on the carbon content $\left(\mathrm{C}_{0}\right)$ :

1,2 - history curves of moisture and organic matter elements total, respectively; 3,4 - history curves of part of organic matter elements total and moisture, respectively.

I, II, III - carbon content variation ranges, respectively $80 \div 86.5$; $86.5 \div 91.5 \%$; and more than $91.5 \%$. 
Table 1. Information concerning content in the moisture samples (W), and organic matter components as per [10], and results of determination of their part in the coal carbonization.

\begin{tabular}{|l|c|c|c|c|c|c|c|c|c|c|c|}
\hline \multirow{2}{*}{ Indicators } & \multicolumn{8}{|c|}{$\begin{array}{c}\text { Content in moisture samples, and organic matter components, } \\
\text { and carbonization parameters at content of } \mathbf{C}_{0} \%\end{array}$} \\
\cline { 2 - 13 } & 80.19 & 81.57 & 84.29 & 86.43 & 88.33 & 89.53 & 90.43 & 91.46 & 92.67 & 93.65 \\
\hline$W, \%$ & 7.34 & 6.44 & 2.59 & 1.59 & 1.15 & 0.99 & 0.88 & 0.78 & 1.29 & 3.32 \\
\hline$\Sigma\left(\mathrm{H}_{0}, \mathrm{O}_{0}, \mathrm{~N}_{0}, \mathrm{~S}_{0}\right), \%$ & 12.47 & 11.99 & 13.12 & 11.98 & 10.52 & 9.48 & 8.69 & 7.76 & 6.04 & 3.03 \\
\hline$W^{a}+\Sigma\left(\mathrm{H}_{0}, \mathrm{O}_{0}, \mathrm{~N}_{0}, \mathrm{~S}_{0}\right), \%$ & 19.81 & 18.43 & 15.71 & 13.57 & 11.67 & 10.47 & 9.57 & 8.54 & 7.33 & 6.35 \\
\hline$C_{n}^{W}$ & 10.93 & 12.67 & 32.54 & 54.36 & 76.81 & 90.43 & 102.76 & 117.26 & 71.84 & 28.21 \\
\hline$C_{n}^{\Sigma}$ & 6.43 & 6.80 & 6.42 & 7.21 & 8.40 & 9.44 & 10.41 & 11.79 & 15.34 & 30.91 \\
\hline$C_{n}$ & 4.05 & 4.43 & 5.37 & 6.37 & 7.57 & 8.55 & 9.45 & 10.71 & 12.64 & 14.75 \\
\hline$\left(C_{n}^{W}\right)^{-1}$ & 0.092 & 0.079 & 0.031 & 0.018 & 0.013 & 0.011 & 0.010 & 0.009 & 0.014 & 0.035 \\
\hline$\left(C_{n}^{\Sigma}\right)^{-1}$ & 0.156 & 0.147 & 0.156 & 0.139 & 0.119 & 0.106 & 0.096 & 0.085 & 0.065 & 0.032 \\
\hline$\left(C_{n}\right)^{-1}$ & 0.247 & 0.226 & 0.186 & 0.157 & 0.132 & 0.117 & 0.106 & 0.093 & 0.079 & 0.068 \\
\hline$\Delta C_{n}^{W}$ & 0.37 & 0.35 & 0.16 & 0.12 & 0.10 & 0.09 & 0.09 & 0.09 & 0.18 & 0.52 \\
\hline$\Delta C_{n}^{\Sigma}$ & 0.63 & 0.65 & 0.84 & 0.88 & 0.90 & 0.91 & 0.91 & 0.91 & 0.82 & 0.48 \\
\hline
\end{tabular}

At the same place, the data on bed moisture in the coal samples, which correspond to the total moisture $(W)$ at the considered coal rank $\left(\mathrm{C}_{0}\right.$ content $)$, are shown.

Dependence diagram of $W$ on $\mathrm{C}_{0}$ changes ambiguously (Fig. 1, Curve 1). During increasing the carbon content up to $86.5 \%$, the moisture content in coal samples is reduced rather intensively by non-linear dependence from 7.34 down to $1.59 \%$. In the carbon content increasing interval of $80 \div 86.5 \%$, reducing of $W$ content takes place less intensively in linear fashion from 1.59 down to $0.78 \%$. Then, in the carbon variation range of $86.5 \div 91.5 \%$, the moisture content growth starts from 0.78 up to $3.32 \%$.

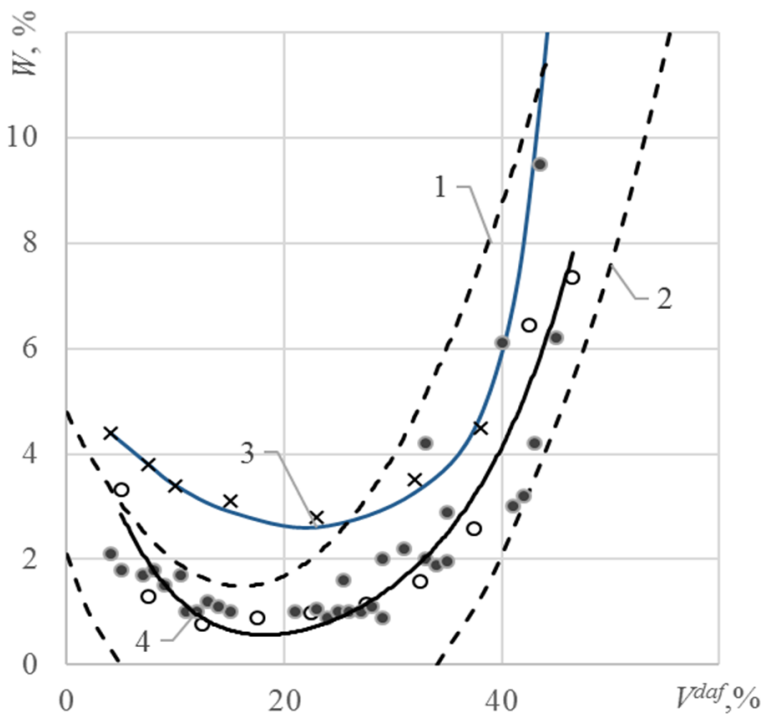

Fig. 2. Total moisture $(W)$ dependence on content of volatile agents $\left(V^{d a f}\right)$ as per data processing [19].

1, 2 are upper and lower limits of moisture content variation in coals [5], respectively; 3, 4 are history curves of averaged moisture values as per [4] and [10], respectively
Such a variation of bed moisture is confirmed by the statistical data [5, 12-14] processing results [19] (Fig. 2). Curve 4 of the averaged data as per [10] is within limits between curves 1,2 of potential individual variation values $W$ for coals of different coal-bearing basins. It witnesses about the initial data [10] reliability, which have been received from the average results of analyses of more than thousand samples of the Donets Basin coals.

\section{Discussion}

Organic matter conversions under elevated temperatures and pressure are complex by nature. The vector direction of organic substance composition variation in case of the metamorphism intensification from lignites to bituminous coals, and then to anthracites is characterized by the carbon content increasing approximately from 70 up to $97-98 \%$, and by the respective reducing of other components totality. For a certain coal layer, content of each main component of organic matter $-C_{o}, H_{o}, N_{o}, S_{o}, O_{o}$, and $W-$ shall be determined by their initial ratio and fluids removal conditions during the metamorphic processes. The combined total of decreasing components $\left(H_{o}, N_{o}, S_{o}, O_{o}, W\right)$ content shall be controlled by the carbon $C_{o}$ content. Dependence of the main components $\left(H_{o}, N_{o}, S_{o}, O_{o}\right)$ total on carbon content is characterized by the functional dependence by nature.

When $C_{o}$ is increasing, individual reduction of the main components content is not so unambiguous. As rule, their links are subjected to non-linear dependences; and in some cases, there are abnormal deviations of some main components from the averaging curves. It evidences about differences between metamorphic conversion intensities of the certain coal layer and averaged indicators. Consequently, the elemental composition and properties of such coal layers will differ from the averaged indicators. These individual differences depend on the content of each component in organic matter. In the course of metamorphism, the oxygen content is reduced 
monotonously from $20-30 \%$ almost down to zero. During increasing the carbon content approximately from 70 up to $87-88 \%$, the hydrogen content is unchanged and within the range of $4-6 \%$. Its abrupt decreasing down to proportions of percent takes place in case of further growth of the carbon content. Reduction of the nitrogen takes place, when the carbon content is more than $95 \%$. The sulphur percentage is almost unchanged in all the coal ranks. For separate coal layers, the total sulphur content may be less than one percent. There are cases of its maximum content up to $10 \%$. The elemental individual content of each component of organic matter characterizes some region of the coal layer metamorphic conversion. Combinations of $C_{o}, H_{o}, N_{o}, S_{o}, O_{o}$, and $W$ relations form the individual properties of coal layers, which are manifested during the mining operations. Work out experience of the separate coal layers and accumulated modern statistical material allow using the analysis results of coal laboratory samples with definition of $C_{o}, H_{o}, N_{o}, S_{o}$, and $O_{o}$. In majority of cases, the modern methodology of moisture determination is related with its drying up to the coal sample constant weight. For this reason, it is not always possible to designate $W$ indicator as dry ash-free organic matter in combination with $C_{o}, H_{o}$, $N_{o}, S_{o}$, and $O_{o}$. The majority of organic matter components are intercorrelated between themselves. They include moisture content as well. $W$ indicator depends on the carbon content, and its non-linear link with the oxygen content is established as well. It evidences that in the first factor block, which determine the coals ignitability, as minimum, it is necessary to consider the elemental relation between $C_{o}, H_{o}, N_{o}, S_{o}$, and $O_{o}$. Content of each of these components individually characterizes one of the aspects of coal layers metamorphic conversion processes. Variation of their relation indicates appearance of the different coal properties in comparison with the previous coal rank.

Based on its unilateral quantitative variation tendency, the carbon is a key indicator of the metamorphic processes intensity. The other components $\left(H_{o}, N_{o}, S_{o}, O_{o}, W\right)$ supplement their characteristics. The most intensive variation takes place in the oxygen and moisture elemental content. The hydrogen content is decreasing essentially in the final metamorphic stages. Minimum variations are observed in the nitrogen and sulphur content. Rank order of the components- $H_{o}, N_{o}, S_{o}, O_{o}$, $W$-based on their part in the carbonization ( $C_{o}$ growth) in the different metamorphic stages influences the chemical activity of coals, including their liability to spontaneous ignition. The most ignitable coals are those, which have the leading places of oxygen, moisture, and sulphur in the rank order by the carbonization indicator.

Using the initial data (Table 1) on relation of the carbon $\mathrm{C}_{0}$ variation and total of other components $\left(\mathrm{H}_{0}, \mathrm{O}_{0}\right.$, $\mathrm{N}_{0}, \mathrm{~S}_{0}$ ) of organic matter, by equation (1), the carbonation indicators $C_{n}^{\Sigma}$ numerical values have been determined in the different coal ranks.

The indicators $C_{n}^{W}$ (Table 1), which correspond to the carbonization intensity $\left(\mathrm{C}_{0}\right.$ increase $)$ at the moisture $(W)$ reduction in samples, have been considered by the equation:

$$
C_{n}^{W}=\frac{C_{0}}{W}
$$

The indicators $C_{n}$ (Table 1), which characterize the general carbonization at decreasing the total of all the components $\left(\mathrm{H}_{0}, \mathrm{O}_{0}, \mathrm{~N}_{0}, \mathrm{~S}_{0}\right)$ of organic matter and bed moisture $(W)$, have been determined based on the dependency:

$$
C_{n}=\frac{C_{0}}{H_{0}+O_{0}+N_{0}+S_{0}+W}
$$

The carbonization indicators $C_{n}, C_{n}^{\Sigma}$, and $C_{n}^{W}$ are interrelated between themselves by the relation:

$$
\frac{1}{C_{n}}=\frac{1}{C_{n}^{\Sigma}}+\frac{1}{C_{n}^{W}}
$$

Values of the indicators $\frac{1}{C_{n}}, \frac{1}{C_{n}^{\Sigma}}$, and $\frac{1}{C_{n}^{W}}$, which correspond to the define metamorphic conversion stage $\left(\mathrm{C}_{0}\right.$ content) are shown in Table 1 .

Having taken $\frac{1}{C_{n}}$ value to be one, for each stage of the coal conversion, parts of $\Delta C_{n}^{W}$ and $\Delta C_{n}^{\Sigma}$ in the general carbonization have been found for moisture and total of other components:

$$
\begin{gathered}
\Delta C_{n}^{W}=\frac{\frac{1}{C_{n}^{W}}}{\frac{1}{C_{n}}}=\frac{C_{n}}{C_{n}^{W}} \\
\Delta C_{n}^{\Sigma}=\frac{\frac{1}{C_{n}^{\Sigma}}}{\frac{1}{C_{n}}}=\frac{C_{n}}{C_{n}^{\Sigma}}
\end{gathered}
$$

The numerical values of indicators $\Delta C_{n}^{W}$ and $\Delta C_{n}^{\Sigma}$ evidence about continuous variation of the relation of parts of organic matter components totality $\left(\mathrm{H}_{0}, \mathrm{O}_{0}, \mathrm{~N}_{0}\right.$, $\mathrm{S}_{0}$ ) and moisture $(W)$ in the different stages of coal conversion (Table 1, Fig. 1). It evidences that in these stages, the coal layers hazardous characteristics will be manifested differently based on the relation between part of moisture and other components.

At the initial stage of the fossil coal conversion $\left(\mathrm{C}_{0} \approx 80 \%\right)$, the part of moisture in carbonization is high enough ( $\Delta C_{n}^{W} \approx 0.36$ ). It decreases abruptly down to 0.12 (Fig. 1 Stage I) at the carbon content increasing approximately up to $86.5 \%$. The part of other components $\left(\mathrm{H}_{0}, \mathrm{O}_{0}, \mathrm{~N}_{0}, \mathrm{~S}_{0}\right)$ increases essentially up to 0.88 . At the following stage (II), the parts of components in carbonization change to a small extent, at $\mathrm{C}_{0}$ content variation in the range of $86.5 \div 91.5 \%$. At the final stage (III) of coal metamorphic conversions $\left(\mathrm{C}_{0}>91.5 \%\right)$, the abrupt growth of moisture part (up to 0.52) in 
carbonization takes place. The analogous decreasing the organic matter components part is down to 0.48 (Table 1, Fig. 1).

Ambiguous change regularities of components of elemental compound of organic mass and various shares of their participation in carbonization are revealed. This allows to establish distinctive signs of separate stages of metamorphic transformations of coal. To reliably predict the dangerous properties of coal seams during mining operations, it is necessary to establish the peculiarities of the processes at individual stages of metamorphic transformations of coal. Each stage of metamorphic transformations of coal must be characterized by at least the following indicators: the percentage of carbon in the organic mass; moisture content; elemental composition of organic matter (hydrogen, nitrogen, oxygen, sulfur); the share of organic matter and moisture components in the carbonization of coal; the direction of change in the percentage of each component of organic matter and moisture with increasing carbonization; the direction of change of an individual share of participation in carbonization of components of organic weight and moisture. Given the actual differences in the elemental composition of the organic mass and moisture content, the prediction of the hazardous properties of each coal seams must be carried out according to the adjusted initial data. The share of participation in the carbonization of coal can be affected by changes in any component of organic matter and moisture. Oxygen, hydrogen, sulfur and moisture play a special role in the manifestation of the dangerous properties of coal seams. The possibility of clarifying the characteristic stages of metamorphic transformations is represented, for the most part, by the results of technical and elemental analyzes of coal. If necessary, in addition to them, it is possible to use data on the petrographic composition of coal. These features of changes in the composition and structure of coal during metamorphic transformations under the influence of moisture are not considered in regulations when determining the hazardous properties of coal seams. These variation particularities in the coals structure and composition during their metamorphism under influence of moisture are not considered in the regulations upon the coal layers hazardous properties determination.

\section{Conclusions}

The conducted researches allow making the conclusions important for the legal environment improvement:

1. The different forms of moisture in fossil coals significantly determine the coal layers hazardous properties: the gasdynamic events, liability to spontaneous ignition and dust-forming capability, coal dust explosibility.

2. Metamorphic conversion intensity during establishing the coal layers hazardous characteristics shall be determined by the useful quality indicators (content of volatile agents, coal plastometric index, semi coking resin yield, free upheaving indicator), which cannot directly characterize changing the elemental composition and properties of fossil coals.
3. Metamorphic conversions intensity is characterized by increasing the carbon content and decreasing the other components in organic and mineral parts composing the fossil coals.

4. Method to found the bed moisture part in coal carbonization has been developed.

5. Study of relationship between the general moisture part in carbonization and that of total of other components of the organic matter evidences not only about the elemental composition conversion, but about the coal inner structure as well.

Content of any form of moisture in the coals shall be considered as the rank index necessary to establish the coal layers hazardous characteristics.

\section{References}

1. D.W. Van Krevelen, Coal: typology-physicschemistry-constitution (Elsevier Science Publishers, Amsterdam (Netherlands), 1993). p 1000

2. M. A. A. Ahamed, et al. Coal composition and structural variation with rank and its influence on the coal-moisture interactions under coal seam temperature conditions-A review article. Journal of Petroleum Science and Engineering 180 (2019).

3. H. Wang, B. Z. Dlugogorski, E. M. Kennedy Role of inherent water in low-temperature oxidation of coal. Combustion Science and Technology. T. 175. (2). (2003).

4. P. Wang et al. Effects of Metamorphic Degree of Coal on Coal Dust Wettability and Dust-Suppression Efficiency via Spraying Advances in Materials Science and Engineering. (2020). https://doi.org/10.1155/2020/4854391.

5. K. L. Cashdollar Coal dust explosibility Journal of loss prevention in the process industries. 9. (1). (1996).

6. Ukraine Ministry of Coal Industry, 10.1.00174088.011:2005. Rules of mining on the seams, which propensity to gas dynamic phenomena (Ukraine Ministry of Coal Industry, Kiev, Ukraine, 2005) p. 221

7. S. V. Janko, S. P Tkachuk. Coal mine ventilation design guide. (Osnova, Kiev, 1994) p. 311

8. P.S. Pashkovskiy et al., KD 12.01.401-96 Endogennyye pozhary na ugol'nykh shakhtakh Donbassa. Preduprezhdeniye i tusheniye. Instruktsiya. Izdaniye ofitsial'noye, (NIIGD, Donetsk, 1997)

9. USSR Ministry of the Coal Industry Coal Mine Dust (Guide Nedra, Moscow, 1979) p. 319

10. V. A. Uspenskij The experience of the material balance of the processes occurring during the metamorphism of coal seams. Petroleum Geology Theoretical and Applied Studies. 1 (2006)

11. Interstate council for standardization, metrology and certification GOST 25543-2013. Ugli burye, kamennye i antracity. Klassifikacija po geneticheskim i tehnologicheskim parametram 
Izdaniye ofitsial'noye. (Standartinform, Moscow, 2014).

12. L. Thomas, Coal geology, 2nd ed. (Oxford, Chichester, Wiley-Blackwell, 2013)

13. Geologo-uglehimicheskaya karta Doneckogo bassejna. Vypusk VIII. Obosnovanie postroeniya geologo-uglehimicheskoj karty Doneckogo bassejna, (Ugletechizdat, Moscow, SU 1954).

14. M.E. Zheldakov, Je.I. Ivanova. Spravochnik po kachestvu antracitov Sovetskogo Sojuza. (Moscow, Nedra. 1980)

15. A.T. Airuni Theory and practice of dealing with mine gases at great depths (Moscow, Nedra. 1981).

16. Q. Zhu Coal sampling and analysis standards. (IEA Clean Coal Centre, London, United Kingdom. 2014)

17. D W. Van Krevelen, Coal: typology - physics chemistry - constitution. (Netherlands: N. p., 1993). Web.

18. N.I. Antoshchenko et al., Establishing hazardous properties of coal mines. Visnik of the Volodymyr Dahl East Ukrainian National University. (2019) doi:10.33216/1998-7927-2019-256-8-7-16.

19. N.I.Antoshchenko, V.D. Shepelevich, Methane in coal seams from formation to emission. (Alchevsk, DonGTU, 2006) p. 267 